\title{
LA ANTÍGONA LATINOAMERICANA COMO LENGUAJE DE LA
} URGENCIA

Latin American Antigone as Language of Urgency

\author{
JAVIERA NÚÑEZ \\ Universidad Nacional Autónoma de México (México) \\ javivalentina@gmail.com
}

Resumen:

El presente ensayo se propone leer desde el concepto de urgencia, algunas de las reescrituras de Antígona en Latinoamérica que se han configurado en torno a procesos de violencia y desapariciones forzadas. Constata, asimismo, la vigencia de la tragedia de Sófocles que se reinventa en la escena contemporánea, bajo la forma de dispositivos capaces de una afectación política tejida como poéticas de la sensibilidad. La urgencia se presenta como impulso creador que los dispositivos elaboran como acontecimiento teatral y aparece no como premura si no como un espacio para la acción, el que no está sujeto a la concepción racional o productiva del tiempo.

Palabras clave: Antígona latinoamericana; urgencia; acontecimiento; desaparición; teatro político.

\section{Abstract}

This essay aims to read from the concept of urgency, some of the rewrites of Antigone in Latin America that have been configured around processes of violence and forced disappearances. It also confirms the current relevance of the tragedy of Sophocles that is reinvented in the contemporary scene, in the form of devices capable of reaching a political dimension through a poetic of sensitivity. The urgency is presented as a creative impulse that the devices elaborate as a theatrical event and appears not as a rush but as a space for action, which is not subject to the rational or productive conception of time.

Key words: Latin American Antigone; urgency, event, disappearance, political theatre.

Alguien cava una fosa, la suya, honda, honda para enterrar todas sus palabras. Alguien se ha quedado sin hermana mayor arrodillada. Alguien no sabe qué sucede. Querría escribir una carta, una larga carta a través del mar,

pero esto tampoco se puede.

Alguien necesita-urgentemente- un arma

en defensa propia.

Alguien quiere vivir a pesar de todo, a pesar de la poesía que nada, nada hizo: que se lavó las manos. ¡Alguien ya no puede más!

Savina Helfgott (1962). 


\section{INTRODUCCIÓN}

El presente ensayo se propone leer, a partir del concepto de urgencia, algunas de las reescrituras de Antígona en Latinoamérica cuyo nacimiento aparece vinculado con procesos historio-políticos en que, la violencia de Estado y las dictaduras, dejaron como consecuencia una gran cantidad de muertos y de personas en calidad de "desaparecidos". Las Antígonas que aquí convocamos - que considero se inscriben en la tradición del teatro político latinoamericano- aparecen para exigir la restitución de los cuerpos y su reincorporación a la historia, a la vez que disputan el reconocimiento del acontecimiento de la "desaparición" y la situación de violencia de la que es víctima la sociedad en su conjunto.

Distingo en las dramaturgias dos operaciones teatrales: en un primero momento histórico -los años sesentas y setentas del pasado siglo- una escritura dramática que se ciñe al concepto de representación y que concibe el teatro como un lenguaje posible para la preservación de la memoria; ello implica que representar las consecuencias de la violencia de Estado, hacer visibles los mecanismos en que se sostienen los totalitarismos, podría habilitar la posibilidad de la justicia y el advenimiento de un nuevo orden político. En este sentido las rescrituras de los sesenta y setenta ponen acento en el sacrificio de Antígona como gesto trágico que, siguiendo a Eduardo Gruner, permitiría la emergencia de lo político.

En esta línea se encuentran las obras: Antígona en el infierno de Rolando Steiner (Nicaragua, 1958); Antígona de Sarina Helfgot (Perú, 1964); La pasión según Antígona Pérez de Luis Rafael Sánchez (Puerto Rico, 1968) y Antígona de José Gabriel Núñez (Venezuela, 1978).

Esta revisión histórica de las dramaturgias en torno al mito de Antígona se sostiene en una pregunta del presente ¿cómo el teatro puede responder frente a los escenarios de violencia y muerte en que vivimos actualmente en México?, ¿es la representación una herramienta que tiene sentido frente a una realidad que a todas luces aparece como irrepresentable?, ¿qué Antígona corresponde a este presente nuestro?

Una posible respuesta se encuentra en el texto Antígona González de Sara Uribe (2012) que es una rescritura contemporánea, construida como una especie de dispositivo textual de memoria, en que se consignan varias Antígonas latinoamericanas que la autora convoca en un proceso de desapropiación. Se conforma de fragmentos textuales de diversa naturaleza, que generan una genealogía de Antígona en Latinoamérica y que, a su vez, permiten dimensionar el problema de la representación cuando media la urgencia de los acontecimientos.

Identifico que, en este último caso, el problema se desplaza desde el anhelo de liberación - de la revolución como horizonte posible, propio de las rescrituras de los sesenta y setenta posteriores a la revolución cubana-, a la necesidad de generar comunidad para hacer frente a un presente de horror y muerte. La escritura política de 
Uribe deja entrever cómo la idea de comunidad subyace en el texto y en el lenguaje, el cual es entendido como un hacer colectivo que, en cierto sentido, carece de autoría $-\mathrm{o}$ si la tiene-, no es otra que una autoría colectiva.

Es de mi interés observar el devenir del personaje de Antígona desde su constitución como "heroína" -en las escrituras de los sesenta y setenta-, hasta las rescrituras contemporáneas -en especial Antígona González-, donde el personaje es construido desde lo "común". Ello con la finalidad de comprender en qué radica su vigencia y su ininterrumpida aparición en los escenarios teatrales de nuestro continente.

Antígona de Sófocles fue estrenada en el año 442 A.N.E. y hasta hoy ha sido representada, pensada y rescrita en incontables ocasiones. George Steiner realizó una exhaustiva revisión del mito sofocleo en su libro Antígona: travesía de un mito universal por la historia de occidente (1979) en el que analiza no solo las dramaturgias vinculadas a Antígona, sino también cómo este mito ha influido en el pensamiento filosófico de todos los tiempos. No fue la intención de Steiner ocuparse del impacto que esta tragedia ha tenido en la historia latinoamericana; de hecho, existen pocos estudios que aborden la dimensión de la presencia de Antígona en nuestro continente; sin embargo, Rómulo Pianacci (2015) ha rastreado el mito de Antígona en las dramaturgias latinoamericanas desde el año 1951 -cuando aparece por primera vez- hasta el año 2015, fecha en que publica su libro Antígona: una tragedia latinoamericana. Este trabajo cumple con saldar una deuda en torno a un panorama latinoamericano, en el que escritoras y escritores que se han apropiado del mito de Antígona para plantear diversas tensiones y problemáticas en relación al poder, la justicia y la recuperación de los cuerpos de los "desaparecidos" durante los procesos dictatoriales.

Por medio de las investigaciones de Steiner y Pianacci, es posible vislumbrar, por otro lado, las sustanciales diferencias entre las rescrituras de la Antígona de tradición europea con aquellas de tradición latinoamericana, como veremos más adelante.

La tragedia Antígona de Sófocles, se inscribe en el llamado ciclo tebano, que está integrado por varios poemas de la época griega arcaica (S. VIII y VII a.c) que versan acerca de los diversos acontecimientos de la vida de Edipo y la guerra entre tebanos y argivos. Se conoce de su existencia gracias a las tragedias que basan sus argumentos en estos mitos durante la época Clásica griega, las que fueron escritas por Sófocles (Edipo rey, Antígona y Edipo en Colono) y Eurípides (Los siete contra Tebas, Las suplicantes y Las Fenicias).

La tragedia de Sófocles titulada Antígona (442 a.C.) cuenta la historia de Antígona, hija de Edipo y Yocasta; hermana de Ismene, Polinices y Etéocles; sobrina de Creonte y prometida de Hemón, su primo. Luego de que Edipo se arrancara los ojos y Yocasta se ahorcara, tras descubrir que su marido y su hijo eran la misma persona, Edipo se va al exilio, acompañado de Antígona quien lo cuida hasta que desaparece en Colono, no sin antes haber maldecido a sus dos hijos varones condenándolos a morir. Los hermanos de Antígona, herederos del trono de Tebas, debían alternarse en el gobierno de 
la cuidad, pero Etéocles no está dispuesto a ceder su turno a Polinicies; entonces este último ataca Tebas con las fuerzas argivas y en la batalla se dan muerte el uno al otro.

Creonte se erige como nuevo rey de Tebas y ordena funerales de Estado para Etéocles, pero condena al cadáver de Polinices a permanecer insepulto para ser devorado por los perros y aves de rapiña; quien intente sepultarlo será condenado a muerte. Antígona, una de sus dos hermanas, desobedece tal ordenanza y brinda ritos funerarios al cuerpo de Polinices, acto en el que es descubierta y condenada a morir de inanición en una cueva. Antígona, contraviniendo una vez más los deseos de Creonte, se da muerte en la cueva y Hemón su prometido, hijo de Creonte, muere junto a ella, también por su propia mano. La esposa de Creonte y madre de Hemón, Eurídice, al enterarse de la muerte de su hijo también se suicida.

\section{DEL ACONTECIMIENTO DE LA VIDA AL ACONTECIMIENTO DEL ARTE}

El concepto de necropolítica habilita una lectura posible para comprender el "tratamiento" del cuerpo de Polinices en las obras que aquí analizaremos. Achille Menmbe (2012) introduce el concepto a partir de su lectura de Agamben y Foucault, para referirse a aquellos gobiernos o figuras de la soberanía cuyo proyecto central es la instrumentalización generalizada de la existencia humana que se concreta en la destrucción material de los cuerpos que son juzgados como desechables o superfluos; o donde los poderes apelan una continua "emergencia" que deriva en una ficcionalización del enemigo, todo ello para acabar con cualquier forma de prohibir la matanza. Bajo estas premisas la política se entiende como "el trabajo de la muerte, en la producción de un mundo en el que se acaba con el límite de la muerte" (Mbembe, 2012, p. 136). Asimismo, Judith Butler en su libro Vida precaria (2004) considera que la vulnerabilidad del cuerpo nos hace comunes y que el dolor puede articularse como recurso político. Sin embargo hay "cuerpos" a los que se niega su existencia en el discurso público, de ahí que haya muertes que ofenden o cuyo duelo no puede expresarse públicamente, lo que conlleva una suerte de "deshumanización": "La deshumanización surge en el límite de la vida discursiva -límites establecidos por medio de prohibiciones y represiones- lo que está funcionando aquí es menos un discurso deshumanizarte que un rechazo del discurso cuyo resultado es la deshumanización" (Butler, 2004, p. 63)

Esta negación del discurso se impone cuando los cuerpos víctimas de la violencia son identificados con los perpetradores de la violencia. Vidas en "estado de suspensión" "entre la vida y la muerte". Las vidas precarizadas, es decir, que carecen de lo mínimo para sobrevivir, encarnan en sí mismas lo que Beatriz Sarlo llama una "deuda":

El cuerpo y el tiempo están unidos: eso es una vida, un cuerpo en el tiempo. La deuda es también una deuda de tiempo porque, cuando el cuerpo no recibe lo que necesita, el tiempo se vuelve abstracto, inaprensible para la experiencia: cuando un 
cuerpo padece, sale del tiempo de la historia, pierde su posibilidad de proyectarse hacia adelante, borra las señales de sus recuerdos (Sarlo, 2010, p. 17).

En la tragedia clásica de Sófocles, la prohibición del duelo público que decreta Creonte al cadáver de Polinices y su condena a ser "devorado por los perros y aves de rapiña" le niega la condición común a los demás cuerpos que lo rodean; el derecho que le otorgaban los dioses de poder transitar al Hades. Para Creonte Polinices pierde su ciudadanía al actuar como un traidor. Quiere castigar ahora el cadáver de Polinices, su memoria, la "dignidad ontológica de su existencia, que desde el momento del nacimiento hasta la muerte hace de cada uno alguien" (Cavarero, 2009, p. 11).

En este sentido Antígona rechaza la ley del Estado que pretende imponerse sobre una ley inmemorial que no es competencia del estado sino de los dioses. El poder desmesurado de Creonte le haría actuar a la misma altura de Zeus, exponiendo así un poder sin límites. Vuelto alimento de los perros, Polinices no es más un hombre, no es más que un ciudadano, no existe para la polis.

Por esa razón el "discurso" de Creonte aparece como "melancólico"-según Butler, ya que no hubo aquí "ni vida, ni pérdida; un discurso en el que no ha habido una condición corporal común, una vulnerabilidad que sirva de base para una comprensión de nuestra comunidad; ni ha habido un quiebre de esa comunidad" (Butler, 2004, p. 63).

Sin embargo, el reclamo que hace Antígona por el cuerpo de su hermano Polinice - en la obra de Sófocles-, no implica solo el asegurarle la vida eterna, va más allá del rito religioso que implica su sepultura; existe en este gesto de enfrentamiento al Estado, una exhortación al reconocimiento del discurso al que ella no tiene derecho. La misma Butler en su libro El grito de Antígona (2001) reflexiona acerca del carácter delictual de Antígona pues no solo desafía la ley: "se apropia de la voz de la ley para cometer un acto en contra de la ley misma" (Butler, 2001, p. 26), Antígona comete dos actos contra la ley, el primero es enterrar a su hermano, y el segundo -más decidor para Butler- es el acto lingüístico de afirmar en público que "Sí, lo confieso, yo digo que lo hice". La autora, que realiza una lectura de la tragedia clásica de Sófocles, como "deformación y desplazamiento" de la ley de parentesco, concluye que "Antígona rechaza obedecer cualquier ley que no reconozca públicamente su pérdida" (p. 42) y en este sentido establece que hay muertes que no pueden ser lloradas en público, por lo que se pregunta: ¿qué nuevos esquemas de inteligibilidad convierten nuestros amores en legítimos y reconocibles, y nuestras pérdidas en verdaderas? (p. 43). Por último, aunque la autora considera que el acto de Antígona "es y no es suyo", supone una transgresión que pone de manifiesto el carácter precario de dichas normas, en este sentido "aunque Antígona muere, su acto permanece en el lenguaje" (p. 42).

El duelo como prohibición que aparece en las Antígonas latinoamericanas, es una forma de la violencia que no solo se extiende sobre el cuerpo muerto, sino también sobre 


\section{Javiera Núñez}

quienes luchan por la acción del duelo. Esta violencia que emana de un ejercicio del poder totalitario niega también la inscripción del acontecimiento en lo social, toda vez que lo social aparece en las Antígonas de los sesenta y setenta como la encarnación de una lucha colectiva frente a un orden político ilegítimo que debe ser combatido y revocado.

En las obras de este periodo (sesenta y setenta) Polinices suele ser presentado como un combatiente o guerrillero, por lo que la negación de su sepultura es consecuencia de su criminalización -el homologar a la víctima con el perpetrador de la violencia, a decir de Butler- y la acción de Antígona "que reitera el acto desafiante de su hermano" (Butler, 2001, p. 27) la convierte también en una delincuente. Enterrar a Polinices, o recuperar su cuerpo desaparecido, es en este contexto un acto político.

Pero ¿cómo tipificar la acción de Antígona en el presente?, ¿cuál sería el carácter político de su acción hoy?, ¿cuál sería su posible rescritura?, ¿a qué poder haría frente?

Nuestro presente aparece como inasible, difícilmente descriptible y en su extrema composición de escenarios del horror, resulta, en ocasiones, inmirable. A Adriana Cavavero (2009), la palabra horror le sirve de base para describir los escenarios del presente y su violencia; llama a los acontecimientos de violencia extrema con lo que convivimos todos los días: horrorismos.

Contrario al terror que se vincula con el impulso de la huida y la autopreservación, el horror implica parálisis: "que encuentra refuerzo en el petrificarse de quien se congela. El movimiento de huida parece por el contrario excluido" (Cavarero, 2009, p. 23). El ser humano en cuanto se encarnado, es ofendido por las formas más extremas de la violencia contemporánea que se manifiesta en desmembramientos o en la violencia que deshace y desfigura el cuerpo:

Aunque se lo transforme en cadáver, la muerte no ofende a la dignidad o, por lo menos, no lo hace mientras que el cuerpo muerto conserve su unidad simbólica, aquel semblante humano apagado ya pero todavía visible, mirable durante algún tiempo antes de la pira o de la sepultura (p. 24).

La parálisis, para Cavarero, no tendría que ver con una reacción instintiva ante la amenaza de muerte, más bien con una repulsión frente a una violencia que, no contentándose con matar, busca destruir la unicidad del cuerpo "y se ensaña en su constitutiva vulnerabilidad" (p. 25).

Las puestas en escena del horror -como ofensas a la "dignidad ontológica de las víctimas"- que pone en juego la violencia contemporánea, hacen naufragar el sentido de los sistemas de referencias sociales y culturales. Allí donde lo que está en juego es la condición humana misma, las prácticas cotidianas se ven forzadas a modificase. El lenguaje no puede más nombrar lo que nombraba; la lengua, incapaz de renovarse para nombrar este tipo de violencia, "tiende a enmascararla" (p. 17). 
El daño al lenguaje es manifestación, a su vez, de un daño a la percepción de la realidad y las certezas; a cualquier percepción existente -hasta el momento del daño o acontecimiento-, que se tenga acerca de la realidad. La guerra, como diría Susan Sontag, "destruye, rompe y allana el mundo construido" (Sontag, 2003, p.16).

Para Slavoj Žižek, una posible definición de acontecimiento sería: "el efecto que parece exceder sus causas -y el espacio de un acontecimiento es el que se abre por el hueco que separa un efecto de sus causas-" (Žižek, 2014, p. 17). Para Alain Badiou el acontecimiento es, ante todo, imprevisible y el ser deviene en sujeto en cuanto manifiesta "fidelidad con el acontecimiento" (Badiou, 1990, p. 260); para que esto sea posible el potencial sujeto debe ser capaz de una "intervención interpretante"; ello quiere decir que debe ejercer el acto de lectura de los síntomas de una situación y su subversión (Laso, 2017, p. 6). Ello tiene como consecuencia la emergencia de lo real, de lo que permanecía oculto o negado. En este sentido el acontecimiento no se produce en sí mismo, sino en los sujetos que leen lo que la situación acusa. Esta interspectiva aparición de lo real generada en el sujeto "fiel al acontecimiento", hace posible la acción. Es aquí donde sitúo la noción de urgencia, como aquel ímpetu estimulado por lo real que genera movimiento; es decir, acción y que permite romper la parálisis horrorista en la que permanece todo aquel que no logra incorporal lo real en cuanto saber.

Las acciones que se elaboran desde la urgencia no son sino el excedente que constituye el acontecimiento; el que -en los casos de las Antígonas que aquí analizamos y sus correlatos en el terreno de lo social-se configura en torno a la disputa por el cuerpo, por el reconocimiento de los cuerpos que son sujetos del daño, por los cuerpos que adquieren la inconcebible categoría de "desaparecidos" y por los cuerpos que, a raíz de esa situación acontecimental, se transforman en cuerpos que buscan, en cuerpos devenidos trashumantes.

Ya que un acontecimiento: "no es algo que ocurre en el mundo, sino un cambio del planteamiento a través del cual percibimos el mundo y nos relacionamos con él. En ocasiones dicho planteamiento puede presentarse directamente como ficción que no obstante nos permite decir la verdad de un modo indirecto" (Žižek, 2014, pp. 23-24). Alain Badiou considera el arte como acontecimiento, y en particular el teatro como acontecimiento capaz de revelar una verdad que permanecía oculta. Además, dentro de la estructura de la tragedia griega, el mismo Aristóteles denomina anagnórisis (o reconocimiento) al recurso narrativo que consiste en el descubrimiento que hace un personaje respecto de su propia identidad, de su entorno o quienes lo rodean, que hasta ese momento ha permanecido oculto. Este descubrimiento produce un giro en la fábula que desencadena hacia su desenlace, y debe generar "compasión y terror" (pathos): "El reconocimiento más aplaudido es cuando con él se juntan las revoluciones, como acontece con el Edipo [...] porque semejante revolución y reconocimiento causará 


\section{Javiera Núñez}

lástima y espanto, cuales son las acciones, de que se supone ser la tragedia un remedo" (Aristóteles, 2015, p. 19).

En este sentido la tragedia es, como diría Badiou, acontecimental. Podríamos, por otro lado, leer la propia acción de Antígona como un acontecimiento que desestabiliza el mundo que se muestra como dado. Su acción pone en evidencia el carácter precario de las normas que le exigen comportarse de determinada manera -diría Butler- y el excedente de dicho descubrimiento destruye por completo la realidad y la certeza que se tuviese de la realidad misma (dígase el suicidio de Antígona, de Hemón y de su madre y el posterior arrepentimiento de Creonte). ¿Pero cuál es la acción de Antígona? Se pregunta Butler, y como mencionamos más arriba, su respuesta se inclina hacia lo performativo de su lenguaje al afirmar que ella enterró a Polinices, al confesar que lo hizo. Este acontecimiento del lenguaje trastoca el mundo de lo posible dentro del universo griego, pues Antígona, por sobre todo, no tiene derecho a hablar. Podría perdonársele su acción si se hubiese declarado ignorante del edicto de prohibición de enterrar a Polinices que emitió Creonte; se la exhorta incluso al arrepentimiento para perdonarle la vida, pero ella insiste en la afirmación de su acción. Es el alegato de su derecho en el terreno de lo público lo que constituye su crimen.

\section{ANTÍGONA VIVE}

La imagen de Antígona retorna al imaginario colectivo frente a las urgencias del presente, la necesidad de simbolizar una acción urgente -como es la de reclamar el retorno de los cuerpos desaparecidos y su derecho a la sepultura-, en una figura que aparezca como común, hace a Antígona portadora de un sentido y de un actuar que el tiempo ha legitimado.

Un ejemplo reciente lo encontramos en una nota de la revista Proceso que apareció en septiembre de 2018 cuando se encontró un tráiler dando vueltas por el estado de Jalisco que contenían en su frigorífico 157 cuerpos fallecidos y que no habían sido identificados; al parecer el tráiler daba vueltas por el estado desde el 2016, ya que las morgues no daban abasto para almacenar tantos cuerpos que esperan su identificación. Antígona busca entre los tráilers de la muerte es el título de la nota que refiere a las madres y familiares de los desaparecidos que se hicieron presentes en el Instituto Jalisciense de Ciencias Forenses (IJCF) con el fin de exigir un trato digno a los cuerpos recuperados y su reconocimiento.

Este abrir o habilitar un relato; esta posibilidad de narrar una experiencia, es la potencia de la figura de Antígona; donde el hecho de nombrarla permite dar forma a una realidad que pareciera indecible. Es en nombre de Antígona que esta periodista quiere hacer visibles a las madres y hermanas que buscan los cuerpos de sus familiares ante el des-amparo de un Estado que muestra su incapacidad o su falta de voluntad en el 
esclarecimiento de los hechos. Cuando estos acontecimientos no son considerados para el Estado urgencias nacionales o más aún a causa de "la distribución desigual de la muerte" (Mbembe, 2012, p. 136) son negados u obscurecidos: "si alguien desaparece y esa persona no es nadie. ¿entonces qué y dónde desaparece, y cómo puede tener lugar el duelo?" (Butler, 2002, p. 59).

Para las madres y hermanas de los cientos de desaparecidos de los últimos años en México la acción de buscar para enterrar, no es sino urgente, pues el acontecimiento que desencadena la desaparición no puede clausurarse. Hasta que Antígona entierre a Polinices, el sentido del tiempo se presenta en su demora y siendo urgente tarda.

Las urgencias abren tiempos otros, o-como diría Anne Tsing, relacionadas con el "tiempo de las urgencias"- abren otros tipos de pensamientos. Donna Haraway, siguiendo a Tsing, rescata: "Las urgencias tienen otras temporalidades, y esas temporalidades son nuestras. Estos son los tiempos en que es imperativo pensar; estos son los tiempos de urgencias que reclaman historias" (Haraway, 2016, p. 7). Sin embargo, la posibilidad de la urgencia en cuanto acción (social, teatral, de creación artística, etc.), se encuentra mediada por el reconocimiento del acontecimiento o la verdad que el acontecimiento revela; así: "el sentido humanitario de lo urgente y lo relevante está mediado, sin duda sobredeterminado, por consideraciones claramente políticas. ¿Qué es lo que se considera urgente y para quiénes?" (Žižek, 2009, p. 11).

Si pensamos las urgencias como tiempo inmediato, que exigen una acción apresurada, el tiempo del pensamiento y la introyección del acontecimiento al mundo de la experiencia sensible se cancela. Es en este gesto de "rapidez" que Žižek instala "falsa urgencia" como límite antiteórico en que se instala el discurso humanitario-liberal progresista acerca de la violencia; un discurso de la violencia, que en su representación se plaga de abstracción y (pseudo) concreción gráfica y que permite decir: "en el tiempo que te toma leer este párrafo diez niños morirán de hambre” (Žižek, 2009, p. 12). Un enunciado de este tipo implica precisamente una anulación que distancia de la urgencia, pues no conlleva movimiento, no inaugura ninguna acción, y es, a mi juicio, solo "alivio de consciencia".

El discurso político determinado por las urgencias particulares de cada contexto, puede configurarse en rescrituras de Antígona - es decir ficciones-, que quieren hacer posible la emergencia de una verdad que permanece oscurecida. Quisieran habilitar una narración que permita hacer emerger el acontecimiento y para ello es necesaria la restitución de los cuerpos. Antígona en Latinoamérica ya no tiene la categoría de enterradora, sino su potencia. Antígona busca para poder enterrar, busca para poder reconocer, reapropiar y reinscribir el cuerpo de Polinices en la historia. La restitución de los cuerpos desaparecidos o asesinados conlleva, a su vez, la posibilidad del acontecimiento, pues los cuerpos que no cuentan, las vidas que no valen y no constituyen ningún discurso; son borradas y por decreto relegadas al olvido: "Nada de esto pertenece 
al orden del acontecimiento. No ha pasado nada. En el silencio de los diarios no hubo ningún acontecimiento, ninguna pérdida" (Butler, 2006, p. 63).

La posibilidad de generar una experiencia, no solo sensible sino también crítica, frente a los acontecimientos que el teatro elabora, obligan a la disciplina a revisar sus propios medios de producción y sus límites frente a lo que es posible o no representar.

Del propio proceso de construir cierta teatralidad, emanan las preguntas que interpelan a la disciplina con relación a su función dentro del entramado social; así el teatro que se sitúa en su momento histórico no podría no interrogarse a sí mismo en relación con los cuerpos. ¿Cómo el teatro - que es un arte de la presencia, de la presencia de los cuerpos, un arte que no existe si no hay un cuerpo frente al otro- se hace cargo del cuerpo en un presente donde los cuerpos no importan? ¿Es una pregunta atingente al teatro? ¿Constituye Antígona una manera de hacerse cargo de los cuerpos que faltan?

\section{LAS ANTÍGONAS REVOLUCIONARIAS/UNA ANTIGONÍA FRENTE A UNA TIRANÍA}

Antígona, en su configuración latinoamericana, ha acompañado procesos sociales emancipatorios en distintos países de nuestro continente; sobre todo entre las décadas del 60 y 70, donde va de la mano con proyectos sociales y políticos, que en algunos casos tienen la posibilidad de la revolución como horizonte. En este período se reescriben Antígonas latinoamericanas que responden de manera concreta a urgencias sociales suscitadas por procesos dictatoriales y que pueden inscribirse en la tradición del teatro político latinoamericano. Desde 1951 -con Antígona Vélez de Leopoldo Merechal-hasta la actualidad, se han escrito al menos 60 Antígonas latinoamericanas. Las Antígonas nacidas en los años sesenta y setenta tienen una fuerte influencia del "teatro épico" de Bertold Brecht y una fuerte orientación marxista, ya que en este período el teatro latinoamericano seguía una de las máximas de Augusto Boal, según este, "puede ser que el teatro no sea revolucionario en sí mismo, pero seguramente es un 'ensayo' de la revolución" (Boal, 1974, p. 148).

Dramaturgos y dramaturgas construyen Antígonas que accionan como sujetos políticos al dotarlas de discurso cuando no tienen derecho a él, al darles agencia, al activar una "resistencia" antihegemónica capaz de imaginar un devenir distinto al que presenta la realidad. Una de ellas es Antígona en el infierno de Rolando Steiner (Nicaragua, 1958).

Este texto dramático tiene como centro de la acción el reclamo de Antígona por recuperar el cadáver de su hermano Polinices, quien fuera secuestrado, torturado y asesinado por el tirano Creonte por formar parte de las tropas rebeldes: "Antígona: Intentan cubrir el delito ocultando el cuerpo de mi hermano [...] ;Sabré hallar el crimen de Creonte y lo que intenta encerrar en las sombras, yo lo sacaré a la luz!' (Pianacci, 2015, p. 251). Rolando Steiner intenta hacer visible el infierno en el que viven los nicaragüenses durante el primer somocismo, el que se prolongaría desde 1937 hasta 1979 en sus tres 
períodos. La exigencia de la recuperación del cuerpo de Polinices concentra el deseo y la lucha por la recuperación de los asesinados por el régimen; Polinices es entonces, uno más de los tantos desaparecidos que son buscados por sus familias: "Arbitrario rey que das furtiva sepultura a tus víctimas; que las ocultas como despreciables botines de guerra y las niegas al duelo de sus madres" (p. 252).

Antígona logra encontrar el cuerpo de su hermano y desenterrarlo, cumple con buscarlo, desenterrarlo y devolverlo a la historia no solo como acción personal, como acción moral, sino, sobre todo, como acción política. Su gesto y su muerte cobran sentido al ser acompañada por el estallido de la revolución popular que al final o derrota al tirano y que su propia hermana Ismene encabeza: “¡Este es día para el que fueron asesinados, mutilados, secuestrados! ¡Del infierno llegan con sus hijas violadas por tus soldados, con el llanto de las madres, ardiendo como fuegos derretidos, para verterlo sobre tu cuerpo!" (p. 253).

Ejemplo de esta lucha continental es también la Antígona de la poeta Sarina Helfgott (Perú, 1964) que sitúa su acción en "un gamonal de un país sudamericano" cuya hacienda es atacada por un grupo de guerrilleros y mueren dos hermanos: Javier/Polinices ${ }^{1}$ y Pablo/Hetéocles. Esta obra trata el tema de los resabios del sistema colonial, la esclavitud de los indígenas y el sojuzgamiento de la mujer peruana. La poeta refleja también la impudicia y el horror de la muerte, desea para Polinices: "la hermosa sepultura del agua, el éxtasis de los ahogados, el sueño de los náufragos" (p. 262). Antígona se enfrenta con su tío Ramón/Creonte, tras cubrir a su hermano con su velo nupcial. Ramón/Creonte trata de seducirla, pero ante su resistencia la asesina con el cuchillo que ella misma porta, al tiempo que grita "ise ha suicidado!”. En ese mismo momento - tal como en la obra de Rolando Steiner- regresan los guerrilleros y la indiada para tomar la hacienda. Antes de morir Antígona defiende la acción de su hermano Javier:

Antígona: poco entiendo de esa revolución. Es que no podía dejar a mi hermano tan desvalido, ese espectáculo, esa repulsión a la vista de todos. La muerte es sagrada, tío. Con un cadáver no se escarmienta. Pero, quizá, después de todo, Javier tenga razón. Sí, mientras existan hombres como tú que trafican con el miedo y la muerte y los exponen públicamente, como lo hacen los comerciantes con sus mercancías. (Pianacci, 2010, p. 262).

Otra de las Antígonas latinoamericanas, que es portavoz de este deseo de horadar una realidad que se presenta como absoluta, es La pasión según Antígona Pérez de Luis Rafael Sánchez (Puerto Rico, 1968). Texto dramático que cumple con "traicionar" la

\footnotetext{
${ }^{1}$ Rómulo Pianacci considera que el personaje de Javier es probable que esté inspirado en el poeta y guerrillero peruano Javier Heraud Pérez, quien vive un tiempo en Cuba donde estudia letras y conoce a Fidel Castro. En este periodo escribe poesía bajo el seudónimo de Rodrigo Machado el que ya utilizaba cuando militaba en el MSP. En 1963 regresa al Perú para emprender la "guerra contra el imperialismo" como parte del Ejército de Liberación Nacional. Muere en mayo del mismo año baleado en medio del río Madre de Dios a los 21 años.
} 


\section{Javiera Núñez}

tragedia de Sófocles para la elaboración de una Antígona del presente; Antígona que tiene la intención de refractar una realidad latinoamericana que el autor describe como una "América amarga, América tomada" cuya acción se sitúa en "la imaginaria república hispanoamericana de Molina". Sánchez narra el pasar de Antígona por la prisión en la que ha sido confinada por enterrar -contra las órdenes del Estado- a los hermanos Tavárez. Este texto hace referencias directas a una realidad donde el dictador -Creón Molina- es eco del dictador dominicano Rafael Trujillo Molina. Encontramos, en voz de Antígona Pérez, la disputa por el cuerpo, no solo en la posibilidad de restituir la identidad a los cuerpos, que en este caso ya han sido enterrados, sino en el ejercicio necropolítico del soberano Creón Molina en los cuerpos:

Antígona: Harán lo más terrible. Lo que rebaje mi honestidad. Lo que sacuda las raíces mismas de mi resistencia. Violarán mi cuerpo con la esperanza de que violan mi espíritu. Como si la lealtad a mis hermanos no estuviera preparada al sacrificio. Harán lo más horrible en sus términos. El cuerpo, me mancharán el cuerpo. Porque Creón sí es el amo de los cuerpos. Pero me dejarán inmaculado el corazón. El corazón es lo que importa (Sánchez, 1968, p. 47).

El corazón de Antígona Pérez - ese lugar intocable- se configura en su compromiso latinoamericano; esta Antígona nacida en Puerto Rico quiere decirse latinoamericana y disputar una pertenencia.

Recordemos que, en 1952, Puerto Rico fue declarado Estado Libre Asociado, con un ambiguo y controvertido estatus político que le otorgaba soberanía parcial sujeta a la legislación y el poder estadounidense. Por otro lado, la relevancia del contexto puertorriqueño se pone de manifiesto al considerar que el personaje de Antígona está basado en Olga Fiscal Garriga, una líder estudiantil del Partido Nacionalista de Puerto Rico que fue sentenciada por la Corte federal estadounidense al negarse a reconocer la autoridad política de Estados Unidos sobre Puerto Rico.

Asimismo, La pasión según Antígona Pérez sugiere que su acción puede situarse en cualquier país donde el poder es ostentado por un dictador o un poder totalitario. Recupera, en este sentido, la pugna que es premisa de la Antígona de Sófocles. La de una concepción de la justicia por parte de Antígona frente a las ordenanzas del Estado que Creonte encarna. Sin embargo, no es preciso hacer una lectura desde la dialéctica que propone Hegel -tomando la cita de George Steiner- en el enfrentamiento de estos dos personajes, pues el filósofo considera el enfrentamiento entre Antígona y Creonte como una colisión entre los principios de la ley familiar, representados por Antígona, y los principios de la ley del Estado representados en la figura de Creonte, "La ley que defiende Antígona -según Hegel- tiene la triple condición de ser: 'natural', 'inconsciente' y es el ámbito del 'pueblo', por tanto, lo que se concibe como 'totalidad' es la persona específica (...) A ella se le asigna una importancia de presencia que se niega a la 'individualidad 
generalizada' del ciudadano en la perspectiva del Estado" (Steiner, 2013, pp. 44-45). En contraposición Creonte, representante de las leyes del Estado, condena la acción de Antígona contra su ordenanza de no sepultar a Polinices, ya que:

[...] el hombre no es más que la obra que ha realizado»; la acción individual no es la acción del Estado racional, por tanto, puede o no tener realidad sustantiva, puede o no justificarse. Siendo esencialmente suya, la acción del individuo hará que este choque con la norma racional de la política del Estado (Steiner 2013, p. 45).

En el caso de las Antígonas latinoamericanas y, en particular en La pasión según Antígona Pérez, su acción no es de carácter individual, Antígona transgrede el mandato del Estado en nombre de la libertad del pueblo o instalándose en el terreno del "nosotros":

Antígona: habrá pues dos versiones de una misma verdad. La mía. La de ellos. La mía es simple. Comienza con mi nombre, este Antígona tenso con el que satisfizo mi padre su inclinación a lo heroico. Sus amigos militares igual que él, eran a admirarme. 'Ven acá Antígona pequeñita, dónde están tus hermanos`. Yo miraba a mi alrededor, sonreía y no sabía que decir. Porque no había aprendido que para llamarse Antígona se necesitan hermanos (Sánchez, 1968, p. 5).

Antígona Pérez, que no tiene hermanos, considera a sus amigos, los hermanos Tavárez, como sus iguales y propios hermanos y está dispuesta a dar la vida por ellos: "Héctor y Mario Tavárez dejaron de ser mis amigos y se hicieron mis hermanos. Los muertos son de sus vivos" (Sánchez, 1968, p. 12). En este sentido, Gina Beltrán Valencia (2014, p. 38) considera que los hermanos Tavárez aluden a Manolo Tavárez Justo, dirigente político del "Movimiento revolucionario 14 de junio" que se oponía al régimen del dictador dominicano Rafael Trujillo. Manolo Tavárez Justo fue esposo de Minerva Miraval, quien junto con sus hermanas fue asesinada en 1960 por el régimen de Trujillo.

Hermandad política e histórica que levanta Sánchez con República Dominicana que también había sido víctima del imperialismo estadounidense como resultado de las llamadas "guerras bananeras": ocupaciones e intervenciones que realizó Estados Unidos en Centroamérica y el Caribe desde 1898.

La diferencia sustancial entre la Antígona latinoamericana que aquí referimos y la heroína griega que recoge la tradición europea-que como sabemos George Steiner se dio a la tarea de rastrear- es fundamentalmente el conflicto que Hegel, según el mismo Steiner, identifica entre las partes.

Antígona de Sófocles encuentra en las leyes inmemoriales de los dioses un sistema moral que la respalda frente a las leyes del Estado; en el caso de Antígona Pérez no hay un poder superior al poder dictatorial de Creón Molina que pueda legitimar su lucha. El poder dictatorial aparece como absoluto. En este sentido, Antígona Pérez es la encarnación de una idea libertaria, un devenir que promete la revolución: 
Antígona: (fuerte) ¿A dónde irás tío Creón, cuando la crisis de tu gobierno tome forma de huelga general o levantamiento o golpe de estado, cuando tengas que escapar precipitadamente en un avión de tu fuerza aérea?

Creon: el pueblo está conmigo, Antígona.

Antígona: (Violenta) ¿Qué harás? No hay tierra franca para ti.

Creon: el ejército es mío, la república es mía.

Antígona: el mundo, el universo son tuyos. ¿A dónde irás Creón destronado? A tocar los tambores para Papa Doc o asilarte en algún país europeo bajo estricta promesa de no iniciar actividades políticas. Derrochador vagabundo de garitos y ruletas, extranjero despreciado, ridículo ex-emperador de América (Sánchez, 1968, p. 64-65).

Las Antígonas que aquí convocamos tienen la acción política como centro y encuentran en la potencia misma de la tragedia y su concepción, un marco para sostener la urgente necesidad de refundar la ley. Esta potencia se encuentra en la tragedia de Sófocles, pero en Latinoamérica se radicaliza al desplazar la acción de Antígona, como acción individual, a la acción colectiva (¿pueblo?); esto es lo que transforma su gesto en un gesto ético, que, si bien nace de la necesidad de un duelo individual - en el caso de Sarina Helfgott y José Gabriel Núñez-, su acción resulta un ímpetu que desencadena un movimiento revolucionario. Esta es también la premisa de Antígona de José Gabriel Núñez (Venezuela, 1978).

Antígona: las grandes causas comienzan por una revolución individual!...(Al General) Claro, tú eres incapaz de verlo...pero ellos sí...(Levanta la voz) ¡Que me miren!...ique me miren y me escuchen!... escúchenme todos los que me vieron nacer...miren bien como me obligan a seguir mi último camino, pero sobre todo, piensen por qué lo hacen...jmiren bien lo que soy...y las leyes que me aniquilan! (Núñez, 1978, p. 62).

Es entonces que el sacrificio de Antígona -en el más alto sentido trágico-se torna en potencia revolucionaria:

Benjamin llama una «violencia fundadora» de una juridicidad diferente a la que sostiene al poder (lo que el poder teme, dice Benjamin, no es a la violencia per se-en qué otra cosa está apoyado el propio poder, 'en última instancia'?-, sino a aquel potencial de fundar una Ley alternativa que tiene la violencia, y por esa vía demostrar que una Ley instituida no es necesariamente la Ley) (Grüner, 2005, p. 23).

Más adelante y en momentos en que el cono sur se encuentra arrasado por las dictaduras y el teatro absolutamente acosado por la censura, en países como Chile y Argentina se representa la Antígona de Sófocles, que por ser una obra de "gran valor universal", logra pasar los filtros de la censura política. La potencia de la obra griega está en la posibilidad de exponer los límites del poder y de reafirmar la posibilidad de la rebelión ante lo que la ley presume como justo. Durante el período dictatorial logra 276 | Alpha No50 (Julio 2020) PÁGS. 263-288. ISSN 07 16-4254 
infiltrar la posibilidad y el derecho a la rebelión ante cualquier decreto que atente contra la vida. "¿Quién no es capaz de evocar a Antígona ante cualquier conflicto que nos desgarre en nuestra relación con la ley que se presenta en nombre de la comunidad como una ley justa?" (Lacan, 1992, p. 293).

Pero, a mi juicio, el gesto dramatúrgico de la reescritura es el único capaz de actualizar y cuestionar la manera en que el poder actúa sobre los cuerpos y de destronar la política como guardiana de lo universal, fracturando la idea del espíritu objetivo encarnado en la Historia. Enfrentar la obra clásica como obra "abierta" sería la única manera de mantenerla viva, o, como plantea Žižek siguiendo a Walter Benjamin: "Actuar como si la obra clásica fuera una película cuyo revelador solo ha sido inventado con posterioridad, de manera que únicamente en la actualidad podemos obtener la imagen completa" (Žižek, 2016, p. 8). El hecho de volver a ponerla en escena, es darle la posibilidad de imaginar mundos posibles para fundar un nuevo habitar, donde su potencial constituyente es hacedero de una emergencia de lo político. Así, volver a escribirla es darle el sentido de sacrificio a la muerte de Antígona, de sacrificio fundacional; tras la muerte de Antígona podría pensarse en un nuevo sentido, podría imaginarse futuro.

Antígona: Tendrás que matar no solo a la muchacha irresponsable que enterró los cadáveres de sus amigos sino a todas las muchachas irresponsables que te saldrán al paso para jugarse la vida, la vida Creón que exige principios hasta a aquellos que insisten en negarlos. Antígona es otro nombre para la idea viva, obsesionante, eterna de la libertad. Las ideas no sucumben a una balacera ni retroceden desorientadas por el fuego de un cañón amaestrado. Ni recortan su existencia porque un tirano inútil decrete pomposamente su desaparición. Matarme es avivarme, hacerme sangre nueva para las venas de esta América amarga. Aligera Creón, aligera. Dame, dame la muerte (Sánchez, 1968, p. 65).

La pasión según Antígona Pérez cita la pasión cristiana en relación con la narración de los momentos antes de la muerte de Cristo en la cruz - que para los católicos representa el "sacrifico" que hace en nombre de los hombres-, muestra la noche antes de la muerte de Antígona, quien ya está presa por haber enterrado a sus "hermanos". En este sentido, el centro del discurso se vuelca al sacrificio como rito fundacional que, según Gruner, es razón de la tragedia:

La tragedia tiene, aquí, un lugar, como si dijéramos, de rito de pasaje. Pero al mismo tiempo, y por ello mismo, es un lugar fundacional: en su mismo centro está el conflicto arcaico entre lo Mismo y lo Otro, que apunta a una separación y al (re)inicio de un nuevo Orden, político, antropológico, pero también subjetivo (Gruner, 2005, p. 29). 


\section{Javiera Núñez}

Siguiendo esta lectura, pasión y pathos evidencian para Sánchez su conexión etimológica, del latín passio (sufrimiento), derivado de passus, participio perfecto pasivo de

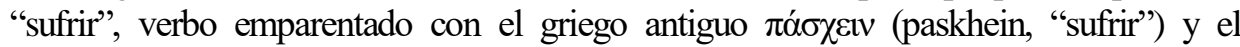

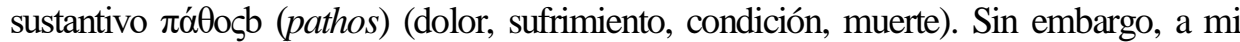
juicio, el sacrificio de Antígona no replica la idea del sacrificio cristiano que apela a la salvación espiritual, como diría Beltrán (2014); aquí el sacrificio se enarbola como violencia fundadora de un nuevo paradigma del que surge lo político en cuanto acción social.

\section{ANTÍGONA ENTRE NOSOTROS}

Las Antígonas latinoamericanas no se pueden circunscribir a una década específica ni solo a contextos dictatoriales. Su recorrido dramatúrgico fijado a inicios de los cincuenta en el siglo pasado se extiende hasta el presente como herramienta de la urgencia política en diferentes contextos de represión social. Por ejemplo, en Antígona González (2012) de Sara Uribe, se podría considerar una cristalización de este lago viaje de Antígona por Latinoamérica; pues contiene en el texto mismo las huellas y signos de las escrituras que lo preceden, es decir, de esas otras Antígonas latinoamericanas. Así, por un lado, constituye una especie de memoria textual que "espejea" una realidad de ruinas con fragmentos que se presentan, si se quiere, como ruinas históricas. Por otro, asemeja un cuerpo en que se inscriben distintos ejercicios del lenguaje. En una poesía que habilita la posibilidad del lenguaje mismo y también la palabra llana, la palabra de a pie, la palabra arrancada de sus más profundas certezas y vuelta a sembrar para decir lo mismo y lo otro; la palabra testimonio, la palabra herida de muerte que no pude preguntar ¿dónde está mi hermano señor policía?

Para contextualizar la obra de Uribe hay que mirar hacia la comunidad de San Fernando Tamaulipas en México, el 11 de abril del 2011, cuando se encuentra una fosa con 72 cuerpos de migrantes que estaban desaparecidos. Este suceso, al que llamaremos catastrófico en cuanto antecede y funda el acontecimiento de la disputa acerca de estos cuerpos, contiene una violencia capaz de desarticular el estado de las cosas, de debilitar cualquier diseño estable y cualquier percepción acerca de la realidad. Hacia 2012, la violencia ya había alcanzado niveles dantescos en México, viéndose incrementados de manera considerable con el inicio de la llamada "guerra contra el narcotráfico" impulsada por el gobierno de Felipe Calderón en 2006; sin embargo, el infierno en el que vivían y viven los tamaulipecos jamás entró dentro del discurso de las urgencias nacionales. $\mathrm{La}$ "guerra contra el narcotráfico" es un conflicto armado continuo que se libra en México a partir del 11 de diciembre de 2006 cuando el gobierno federal anunció un operativo contra el crimen organizado en el estado de Michoacán. Desde el inicio del conflicto se movilizó a la policía federal en compañía de los cuerpos de seguridad de cada entidad federativa y de diversos municipios y a ellos se sumó el ejército y la marina. Es preciso decir que las 
consecuencias catastróficas de esta guerra para la población civil apenas fueron documentadas por la prensa. En el caso de Tamaulipas, solo se informó el $13 \%$ de los sucesos relacionados a esta "guerra" que dejó miles de muertos colaterales, detenciones ilegales y convirtió al país en un verdadero campo de batalla² .

Uribe, en un diálogo con la revista Nexos, ha contado que fue convocada por la actriz Sandra Muñoz a escribir una Antígona que hablara respecto de Tamaulipas para ser puesta en escena; pero en una primera instancia dudó en emprender aquel desafío, dejando que la idea le fuera rondando hasta que aparecieron los 72 cadáveres de los migrantes en San Fernando. Uribe cuenta que se encontraba ese día en un recinto estatal y que no se hizo mención alguna acerca de dicho hallazgo: "Esa mañana, la normalidad ininterrumpida que el Estado mismo proclamaba era un gran letrero que decía: aquí no ha pasado nada" (Villaneda, 2017).

Es la negación absoluta del acontecimiento - parafraseando a Butler (2002)- lo que moviliza a la urgencia de la enunciación de los hechos. La necesidad de arremeter con el lenguaje contra la supuesta normalidad, contra la autocensura, el miedo y la negación de la propia sociedad, de asumir el "estado de guerra" y sus muertos consecuentes. Una sociedad que, como Ismene, permanece inmóvil; que se ve forzada a "torcer" el lenguaje en eufemismos porque hay miedo: "Muy al principio hubo quien aseguraba que todo eran paranoia y rumores y lo que hablaba por su boca era el miedo, el pavor de aceptar que estábamos en medio de una gran balacera llamada guerra contra el narco" (Villaneda, 2017). El discurso social del miedo es la razón del silencio, de la huida o la parálisis; es el mismo miedo que impide a Ismene -en la obra de Sófocles-, ayudar a Antígona a dar sepultura a Polinices, y que la deja como un personaje medroso, cuyo arrepentimiento llega demasiado tarde: "Esta percepción física del miedo o, si se quiere, esta reacción física al miedo, sintomáticamente, no solo alude al movimiento, por así decir local, del cuerpo que tiembla, sino que también alude al movimiento, mucho más dinámico, del huir" (Cavarero, 2009, p.19).

En la Tebas-Tamaulipas de Uribe, Tadeo González es el hermano desaparecido, no hay aquí un cuerpo yerto que deba o pueda ser enterrado, lo que hay es la imposibilidad de asumir a Tadeo González como muerto, pues está "desaparecido" y es en esta incomprensible categoría, donde debe indagar quien busca: "Un vaso roto. Algo que ya no está, que ya no existe. Que se halla en paradero ignorado, sin que se sepa si vive. Sin que se sepa" [sic] (Uribe, 2012, p. 18).

El desaparecido expone un límite, un límite en el lenguaje y en el mundo, solo deja como resto la ausencia. Su lugar es un "no lugar" entre la vida y la muerte, no declarado

\footnotetext{
${ }^{2}$ En: https://www.animalpolitico.com/2017/01/guerra-narco-calderon/

${ }^{3}$ De aquí en adelante las itálicas en las citas de Antígona González corresponden a la autora. Las utiliza para identificar los textos citados de otras fuentes.
} 


\section{Javiera Núñez}

muerto, pero imposible de ser declarado vivo. En este sentido, el acontecimiento de la desaparición se extiende en el tiempo, un acontecimiento que no puede ser clausurado en cuanto el cuerpo del desaparecido no se haga presente. La figura del desparecido es puro acontecimiento, herida abierta o puro silencio:

Con los detenidos-desparecidos nada de lo que habitualmente encaja lo hace. Nada: los cuerpos se separan de las identidades y hasta las palabras se disocian de las cosas. Terrible, la figura del detenido-desaparecido es una irrupción en el sentido que supera a los instrumentos que lo dan, que desconcierta al sentido mismo emplazándose en el terreno pantanoso de las catástrofes sociales y lingüísticas (Gatti, 2006, p. 27).

La figura del desaparecido pone en el centro la idea del duelo. No el duelo entendido solo como aceptación de la muerte -ya que la muerte aquí es una intuición-, pero la categoría de "desparecido", en el lenguaje, impide la certeza de la muerte vinculada al cadáver. Al cuerpo en que se inscribe el crimen. Pensar que "sin cuerpo no hay delito", es clausurar también la posibilidad de justicia, es decir, que además de las razones del afecto, la religión o la ética de la verdad, el recuperar los cuerpos significa posibilidad de justicia.

Para Gabriel Gatti, lo que resulta catastrófico es la imposibilidad de representar al desaparecido, pues se encuentra en el terreno de lo indecible. Por ello, contrapone al concepto de "invisible" el de "vacío": "algo que es, pero no se puede ver, algo que existe, en donde hay cosas, pero cosas que siempre escapan de los instrumentos que inventamos para pensar las cosas. Un espacio habitable; pero a todas luces irrepresentable" (Gatti, 2006, p. 31). Así -siguiendo a Gatti-, las artes serían las únicas capaces de abordar este problema de representación, y lo han hecho sin duda, llegando precisamente a los límites de lo que es posible y representable. Sin embargo, para el teatro en particular la representación también se ha vuelto una cuestión problemática.

Antonin Artaud ya había decretado que el teatro no es representación de la vida, o al menos el teatro de la crueldad: "El teatro de la crueldad no es una representación. Es la vida misma en cuanto ella tiene de irrepresentable. La vida es el origen no representable de la representación", cita Derrida, y renglones más abajo: "El arte no es imitación de la vida, mas la vida es imitación de un principio trascendente con el cual el arte nos pone de nuevo en comunicación" (Derrida, 1969, p. 8). En este sentido, la mimesis aristotélica constituye la forma más ingenua de representación. Gatti considera que solo el arte ha sido capaz de hacerse cargo de estas contradicciones, poniendo en escena la propia imposibilidad de representar: "representar lo irrepresentable representando la imposibilidad de representarlo" (Gatti, 2006, p. 34).

Gilles Deleuze planteaba que cuando el teatro permanece representativo, toma por objeto los conflictos, oposiciones o contradicciones son representaciones que no implican una especial dificultad, porque son "productos" sociales que de alguna forma han sido 
normalizados en el tejido discursivo de lo social. Por tanto, poner en el centro el conflicto del Estado contra el individuo no tendría potencia alguna -según Deleuze-, más bien habría que indagar en lo que no está normalizado, lo que permanece indecible o irrepresentado. Asumir una función antirrepresentativa permitiría construir una figura de una conciencia minoritaria, en que la "minoría" aquí designa "la potencia de un devenir" mientras que la mayoría "señala al poder o la impotencia de un estado, de una situación. Es aquí donde el teatro o el arte pueden surgir con una función política específica" (Deleuze, 2003, p. 97-102).

La obra de Uribe se inscribe en ese territorio de la "potencia de un devenir", ya que el conflicto está puesto en los cuerpos, en todos los cuerpos implicados en el acontecimiento de la desaparición; una obra que no puede ni debe situarse dentro de alguna corriente o forma específica de lo que entendemos como "arte" o "teatro contemporáneo", sino como un ejercicio que apela a generar comunidad dentro de los escenarios del horror. Así, cuando Antígona González le habla a su hermano Tadeo, lo evoca como quien escribe una carta, en la voz epistolar que deja abierta siempre la posibilidad de respuesta, que es posibilidad de futuro o es quizá la estrategia íntima de la elaboración del duelo por el otro, que en un espacio de ensoñación se hace con el otro. "La imaginación intenta futuro", diría Bachelard (Bachelard, 2011, p. 20). Esta modalidad de la voz es quizá la réplica de uno de los materiales que Uribe utiliza para la escritura de su Antígona: la voz de Diana/Antígona Gómez, una actriz colombiana que elabora un blog llamado Antígona Gómez. No olvido porque no quiero, cuyas entradas, desde 2007 hacen referencia a su padre Jorge Gómez, desaparecido el 21 de marzo de 2006 y cuyos restos fueron hallados el 23 de abril del mismo año.

El gesto epistolar desde el que Antígona González habla a Tadeo González, y le otorga un lugar en que habitar; este lugar sería el no lugar del limbo. El limbo como espacio entre la vida y muerte, que el catolicismo antiguo otorgaba a quienes debían esperar el juicio final. El limbo como espacio de indeterminación, como no estar en ningún lado preciso, en un ínter, en una espera de que algo suceda: "¿es posible entender ese extraño lugar entre la vida y la muerte, ese hablar precisamente desde el límite?" (Uribe, 2012, p. 27). Limbo que también habita Antígona, cuya acción la sitúa en ese ínter en que está viva y condenada a muerte. No solo el desaparecido habita en este imaginario limbo, sino también quienes buscan a ciegas, quienes no reciben respuestas, a quienes se les niega hasta la existencia de su ser amado: "aquí todos somos limbo", "aquí nuestro presente parece suspendido" (pp. 63 y 73). El vacío que nombra Gatti deviene en limbo, al pensarse desde los que sobreviven, desde los que habitan el acontecimiento de la desaparición del otro y empiezan de alguna manera a desaparecer: "¿Cuántos desaparecidos? Por mí pueden seguir rebajando las cifras, no importa, con uno que desaparezca estamos condenados al olvido, a la nada, al limbo" (Gómez, 2007, s/p). Para 


\section{Javiera Núñez}

no desaparecer la estrategia es nombrar, Antígona González dice: "todos aquí iremos desapareciendo si nadie nos busca, si nadie nos nombra" (Uribe, 2012, p. 95).

\section{YO LES DIGO QUE SIN CUERPO NO HAY REMANSO}

El problema de la recuperación de los cuerpos es central en Antígona González, la vulnerabilidad del cuerpo y como el poder aparece como administración de la vida, como el poder soberano: "no puede ser otro que el poder ilimitado de decisión sobre la vida" dentro de un constante Estado de Excepción que permite convertir al humano (bios) en animal (zoe) (Iglesias, 2009, p. 3). La Tebas-Tamaulipas es territorio de este permanente Estado de Excepción donde la idea del "coro" como pueblo, es tomado de distintas plataformas que generan narrativas respecto del estado de cosas en Tamaulipas. Una de ellas es el proyecto Menos días aquí, un blog donde voluntarios dedican algunos días de su vida a contar muertos, a nombrarlos; la misma Uribe se desempeña como voluntaria contando muertos a finales de 2011 (ella cuenta 299 muertos); de esta manera abre la primera parte Antígona González de Uribe, titulada "instrucciones para contar muertos", frase que recibe la propia Uribe en un correo electrónico cuando se ofrece como voluntaria del proyecto:

Uno, las fechas, como los nombres, son lo más importante. El nombre por encima del calibre de las balas.

Dos, sentarse frente a un monitor. Buscar la nota roja de todos los periódicos en línea. Mantener la memoria de quienes han muerto.

Tres, contar inocentes y culpables, sicarios, niños, militares, civiles, presidentes municipales, migrantes, vendedores, secuestradores, policías.

Contarlos a todos.

Nombrarlos a todos para decir: este cuerpo podría ser el mío.

El cuerpo de uno de los míos.

Para no olvidar que todos los cuerpos sin nombre son nuestros cuerpos perdidos.

Me llamo Antígona González y busco entre los muertos el cadáver de mi hermano (Uribe, 2012, p. 13).

La tarea de contar, nombrar y restituir a los muertos es una tarea que tiene que ver con "los cuerpos, con la ausencia y con el lenguaje":

(...) Se trata de integrar y asentar de manera sucinta, en el caso de las entradas del blog, y con una brevedad quirúrgica, en el caso de los tuits, el lugar del hallazgo, las circunstancias y características en que ha ocurrido un homicidio, una ejecución, en que ha sido hallado un cuerpo sin vida" (Uribe, 2017, p. 48).

El esfuerzo por elaborar, mediante el lenguaje, un texto informativo respecto de los cuerpos abatidos, expone la manera en que las palabras -aunque quieran ser desprovistas 
de emoción o identificación, aunque pretendan objetividad- se resisten y traen consigo imágenes que vuelven el texto informativo algo más: "Tierra Colorada, Guerrero. 18 de febrero. El cuerpo sin vida de un hombre fue encontrado en la presa La venta. Aunque todavía no ha sido identificado, su brazo izquierdo tenía un tatuaje con el nombre 'Josefina', y en el brazo derecho llevaba marcado el nombre 'Julio"' (Uribe, 2012, p. 46).

El tránsito de un medio a otro en este ejercicio de desapropiación permite a Uribe la elaboración del "coro" como esta voz colectiva. Esta voz que para la tragedia clásica se trata del pueblo, de quien observa las peripecias del héroe y opina respecto de la acción. Aquí la voz coral es testimonial; el coro se construye con las frases que se repiten en la búsqueda de los familiares, los lugares afectivos que estos manifiestan en su discurso.

La relaboración de Antígona, en este caso, se aleja de cualquier presupuesto representativo de la realidad; la realidad se presenta como inasible e inenarrable y es condición del discurso. Su veracidad se manifiesta en su dislocación. En esta dirección, el cuerpo textual de Antígona González, que de alguna manera replica la imagen de un cuerpo roto, tiene posibilidades de generar afectación -empatía si se quiere- y se inscribe, sin saberlo quizá, dentro de las escrituras teatrales que se ubican en los límites disciplinares.

Es esta una escritura política del "nombrar", del restituir el acontecimiento a la historia, de poner el cuerpo propio junto al cuerpo que falta y junto al cuerpo que busca: "Soy Sandra Muñoz, vivo en Tampico, Tamaulipas y quiero saber dónde están los cuerpos que faltan. Que pare ya el extravío" (Uribe, 2012, p. 14). El cuerpo de Muñoz -quien encarna a Antígona González sobre el escenario-y de quienes son espectadores de la obra establecen una correlación situada en un tiempo y un espacio, un estar con otro y de frente, enfrentar la ficción a la vida. La dimensión corporal que no puede eludir la escritura teatral. Uribe escribe su texto pensando en el teatro, en que es un texto para el teatro y el teatro tiene como materialidad primera el cuerpo.

Esta acción de nombrar desde los que sobrevivimos se traduce en un actuar desde la urgencia, no en la abstracción de la muerte y la violencia que cae sobre el mundo, sino en concreto nombrando y contado, a los otros, a los que buscan, a uno mismo. Es en este sentido, que el texto se inscribe en la lógica de la desapropiación y que siguiendo el gesto de una Antígona latinoamericana se desplaza de la acción personal hacia la posibilidad del nosotros. La desapropiación -concepto tomado de Cristina Rivera Garza (2013) en que la propia autora se inscribe- implica definir el lugar de la lectura que hace la autora como una: "práctica productiva y relacional, es decir, como un asunto del estar-con-otro que es la base de toda práctica de comunidad, mientras esta produce un nuevo texto, por más que parezca el mismo" (p. 268).

El ejercicio autoconsciente de Uribe, de una dramaturgia desde las reescrituras de Antígona en Latinoamérica, colocando al personaje frente a la realidad, supone el choque de lo escrito contra la posibilidad de Antígona en el presente, ese espacio en que causa y efectos chocan y el cuerpo Antígona González deviene excedente del acontecimiento. 
:La interpretación de Antígona sufre una radical alteración en Latinoamérica -en donde Polínices es identificado con los marginados y desaparecidos.

: Escrita como un largo poema en verso libre, el texto contiene innumerables fragmentos de letras de tango, que, en su distorsión y alteración, plena de nuevos significados y entrecruzamientos

: en su distorsión y alteración Polínices es identificado con los marginados y desaparecidos

: en su distorsión y alteración Polínices es Tadeo (Uribe, 2012, p. 21).

La autora pone en evidencia este ejercicio autoconsciente marcando el texto, cada vez que en la obra aparecen las cursivas, sabemos que alguien más ha hablado en el pasado, que algún espectro textual se asoma, que hay otros muertos que anteceden el texto y que las identificaciones históricas de Antígona trascienden el tiempo:

Renunciar a lo que se posee: eso significa desposeerse. En este caso, la desposesión señala no solo el objeto sino la relación desigual que hace posible la posesión, en primer lugar: el dominio. Una poética de la desapropiación bien puede involucrar estrategias de escritura que, como las apropiacionistas, ponen al descubierto el andamiaje de tiempo y el trabajo comunal, tanto en términos de producción textual como en tiempo de lectura. (Rivera Garza, 2013, p. 270).

Lo que Uribe escribe tiene, sin duda, la huella de la comunidad; como mencionamos más arriba, la presencia del coro en su Antígona se levanta desde el proyecto "menos días aquí", pero también del testimonio, de las palabras de quienes buscan. Testimonios que la autora conoce y que son sustento de la escritura ética, de su especial cuidado con el tema de la desaparición. El habilitar la posibilidad de la comunidad desde la escritura como dice Rivera Garza (2013): "Pensar la comunidad, que es pensar el afuera del sí-mismo y la aparición del entre que nos vuelve nosotros y otros a la vez, es una tarea sin duda de la escritura. Acaso esa sea, en realidad, su tarea, de tener una. Su razón de ser, de tener solo una" (p. 272).

Inferimos, en el texto de Uribe, una necesidad de habilitar la posibilidad de comunidad, no como un presupuesto de la reunión que brinda el acontecimiento teatral mismo, sino en la idea del nosotros como un estar-en común, de un daño que nos implica o, como diría Ilena Diéguez (2016), de habitar una communitas del dolor, en que el estar en común en relación con la imposibilidad del duelo, a la negación del duelo, revela a la figura de Antígona en cada uno de nosotros. Esta posibilidad de comunidad es también "la potencia de un devenir" deleuzeano y que se articula en la experiencia afectiva conjunta.

De ahí la importancia de dolerse. De la necesidad política de decir «tú me dueles» y de recorrer mi historia contigo, que eres mi país, desde la perspectiva única, aunque generalizada, de los que nos dolemos. De ahí la urgencia estética de decir, 
en el más básico y también en el más desencajado de los lenguajes, esto me duele. (Rivera, 2015, p. 11).

Y aquí el dolerse tiene que ver con la convicción de la vida y su fragilidad, por lo mismo Antígona González no muere, no puede morir porque no ha cumplido con encontrar a su hermano; muere sin duda de otra manera, pero el vivir es una forma más del compromiso con la memoria: "por eso te pienso todos los días, porque a veces creo que, si te olvido, un solo día bastará para que te desvanezcas" (Uribe, 2012, p. 39).

\section{ALGUNAS CONCLUSIONES}

La pregunta por el cuerpo de Polinices es la que levanta todo el andamiaje de Antígona González. Todo lo que puede implicar la pregunta ¿dónde está? Que se refracta en una pregunta colectiva ¿dónde están?, llena de terribles resonancias históricas para Latinoamérica que parece no ausentarse de estas disputas. Donde aparece una Antígona hay detrás una urgencia, una urgencia no reconocida, invisible o invisibilizada por el poder de turno. Una urgencia que encuentra en Antígona y su historia, la posibilidad de articulación de una demanda de justicia o la puesta en escena del gesto rebelde, el recuerdo de la posibilidad de rebeldía frente a lo que daña, lo que mata, lo que desaparece, "frente a lo que desaparece, lo que no desaparece" (Uribe, 2012, p. 45), el afecto, el compromiso, la dignidad, la autonomía.

En las Antígonas contemporáneas la representación del poder es imposible; por un lado, hay una renuncia a la representación, pero, por el otro, también hay una imposibilidad. ¿Quién es el que impide que los cuerpos sean devueltos a sus familiares? ¿Quiénes? ¿Quién orquesta la muerte? El poder aparece aquí como un límite, y así también las instituciones; no hay a quién reclamar, ante la negación de los hechos, no hay a quién preguntar y por respuesta solo silencio.

Yo crei que iba a entrar en el pueblo de los muertos,

Mi patria.

Tú eras la patria.

Pero ¿la patria no estaba devastada?

¿no había peste en la ciudad, ¿No se hacían invocaciones a los dioses inútilmente?

Yo supe que vería una ciudad sitiada.

Supe que Tamaulipas era Tebas

Y Creonte este silencio amordazándolo todo. (Uribe, 2012, p. 65)

Imposible representar a Creonte, o más bien imposible pensar a un tirano cruel. El poder aquí se presenta como un permanente Estado de Excepción, que los regímenes demoliberales sustentan en la exclusión "como excepcionalidad permanente en el control 


\section{Javiera Núñez}

de la vida" (Iglesias, 2009, p. 6). Tadeo González y Antígona González se encuentran bajo el régimen de la exclusión y así también los "desaparecidos", los migrantes, los pobres y quienes buscan.

[...] la limpieza administrativa aplicada sobre la vida es la excepción convertida en regla de la política moderna. Como nos recuerdan cada día los muros construidos para ejercer el poder soberano de la exclusión. Polinices sigue hoy pudriéndose en las puertas de todas las murallas levantadas por poderes soberanos (Iglesias, 2009, p. 6).

En este sentido, la vigencia de Antígona es incuestionable, ya que se transforma en un referente indiscutible de rebeldía, pero sobre todo de reivindicación de la lucha afectiva contra un poder que excluye o que niega la condición de sujeto a quienes le parecen prescindibles. Cada día aparecen nuevas Antígonas: hijas, madres o hermanas que luchan por encontrar los cuerpos de sus seres amados, que defienden su derecho al duelo y que no descansan, incluso hasta el punto en que la muerte las alcanza. La legión de Antígonas que recorre nuestro continente, palas en mano para desenterrar cuerpos, para volver a ponerlos en la tierra bajo el deseo más amoroso, tras la ilusión de que tengan "la hermosa sepultura del agua, el éxtasis de los ahogados, el sueño de los náufragos" y que por fin descansen, ellas y ellos. Pero también con el feroz reclamo de que sus nombres sean reconocidos, de que dejen de ser "cadáveres" para volver a ser hijos, hijas, hermanos, hermanas, para que vuelvan a ser nuestros.

La investigación que sustenta este ensayo se titula La Antígona Latinoamericana como lenguaje de la urgencia. Perspectivas de lo político en la producción teatral latinoamericana 2000-2016. Y fue realizada gracias a la beca posdoctoral otorgada por la Dirección General de Asuntos del Personal Académico (DGAPA) de la Universidad Nacional Autónoma de México, entre agosto de 2018 y julio de 2019. La investigación se realizó en el Centro de Estudios Latinoamericanos (CELA) de la Facultad de Ciencias Políticas y Sociales, bajo la tutoría de la Dra. Rossana Cassigoli Salamon.

\section{OBRAS CITADAS}

Aristóteles (2015). Poética. ebook: Booklassic.

Badiou, Alain (1999). El ser y el acontecimiento. Buenos Aires: Manantial.

Beltrán, Gina (2014). "Antígona Pérez y el sensacionalismo: La desarticulación de un sistema totalitario" $452^{\circ} \mathrm{F}$ : Revista de Reoría de la Literatura y Literatura comparada [en línea], Núm.10: (35-49). disponible en: 
https://www.raco.cat/index.php/452F/article/view/275816/363760 [Consultado 02 de septiembre de 2018]

Boal, Augusto (1974). Teatro del oprimido y otras poéticas políticas. Buenos Aires: La Flor. Butler, Judith (2006). Vida precaria. El poder del duelo y la violencia. Buenos Aires: Paidós.

— (2002). Cuerpos que importan. Buenos Aires: Paidós.

— (2001). El grito de Antígona. Barcelona: El Roure.

— (1997). Lenguaje, poder e identidad. Madrid: Síntesis.

Cavarero, Adriana (2009). Horrorismo. Nombrando la violencia contemporánea. México: Anthropos.

Cornago, Óscar (2006). "Teatro y poder: estrategias de representación en la escena contemporánea", Revista Iberoamericana. VI, 21, 2006: 71-90.

Cróquet Pedrón, Eleonora (2000). El gesto de Antígona o la escritura como responsabilidad. Santiago: Cuarto Propio.

Deleuze, Gilles (2003). Superposiciones. Buenos Aires: Artes del sur.

Derrida, Jacques (2012). Espectros de Marx._Madrid: Trotta. (1989). La escritura y la diferencia. Barcelona: Anthropos.

De Vicente, Cesar (2013). La escena constituyente. Teoría y práctica del teatro político. Madrid: Centro de documentación crítica.

Gatti, Gabriel (2006). "Las narrativas del detenido-desaparecido (o de los problemas de la representación ante las catástrofes sociales)", Confines 2/4 agosto-diciembre: 27-38.

Gómez, Antígona (2007). "Desaparecidos... cómo, por quién, por qué?, Antígona Gómez [Blog] jueves 30 de agosto de 2007. Disponible en:

http://antigonagomez.blogspot.com/2007/08/ [consultado el 20 de mayo de 2019].

Haraway, Donna (2016). "Tentacular thinking: Anthropocene, capitalocene, chthulucene", E-flux journal \# 75- September 2016 [en línea]. Disponible en: https://www.eflux.com/journal/75/67125/tentacular-thinking-anthropocene-capitalocenechthulucene/ [Consultado el 23 de mayo de 2019].

Iglesias Turrión, Pablo (2009). "Los muros de Tebas. La política como decisión sobre la vida o Agamben contra Agamben", Nómadas. Critical Journal of Social and Juridical Sciences, 24 (4): 105-113.

Lacan, Jacques (1992). La ética del psicoanálisis. Buenos Aires: Paidós.

Laso, Eduardo (2017). "Acontecimiento y deseo (Un comentario a la lectura de Zizek sobre la obra de Alain Badiou)", Aesthethika. International journal on culture, subjectivity and aesthetics, Vol. 3, (1), Spring/Primavera 2007: 4-13.

Mbembe, Achille (2012). "Necropolítica. Una revisión crítica" en Chávez McGregor, Helena (Curadora). Estética y violencia: necropolítica, militarización y vidas lloradas. México: MUAC, 130-139. 
Menos días aquí (2019). Proyecto colectivo. Contamos muertes por violencia en México. Mantenemos viva la memoria de nuestros muertos. Reclamamos paz. [Blog]. Disponible en http://menosdiasaqui.blogspot.com [Consultado en enero de 2019]. Pianacci, Rómulo (2015). Antígona: una tragedia latinoamericana. Argentina: Losada.

Richard, Nelly (2007). Fracturas de la memoria. Arte y pensamiento crítico._Argentina: Siglo XXI.

Rivera Garza, Cristina (2015). Dolerse: Textos desde un país herido. México: Surplus.

- (2013). Los muertos indóciles. México: Tusquets.

Sanchez, Luis Rafael (1968). La pasión según Antígona Pérez [pdf] (libreto). Disponible en:http://smjegupr.net/wp-content/uploads/2012/07/La-pasión-según Ant\%C3\%ADgona-Pérez.pdf

Sarlo, Beatriz (2005). Tiempo pasado. Cultura de la memoria y giro subjetivo. Una discusión. Argentina: Siglo XXI.

Uribe, Sara (2017). “¿Cómo escribir poesía en un país en guerra?” Tintas. Quaderni di letterature iberiche e iberoamericane núm. 7: 45-58. (2012). Antígona González. Oaxaca: Sur +.

Villeda, Karen (2017). "¿Me ayudarás a levantar el cadáver? Diálogo con Sara Uribe” Nexos, 16 de febrero de 2017 [en línea]. Disponible en: https://cultura.nexos.com.mx/?p=12147 [consultado el 20 de enero de 2019].

Žižek, Slavoj (2016). Antígona. España: Akal.

— (2014). Acontecimiento. Madrid: Editorial Sexto Piso.

— (2009). Sobre la violencia. Seis reflexiones marginales. Argentina: Paidós. 